\title{
IMPACT OF TECHNOLOGY INVESTMENT ON FIRM'S PRODUCTION EFFICIENCY FACTOR IN MANUFACTURING
}

\author{
Martina NOVOTNÁ(D) $1^{*}$, Tomáš VOLEK (D)1, Michael ROST², \\ Jaroslav VRCHOTA ${ }^{3}$ \\ ${ }^{1}$ Department of Economics, Faculty of Economics, University of South Bohemia, \\ České Budějovice, Czech Republic \\ ${ }^{2}$ Department of Applied Mathematics and Informatics, Faculty of Economics, \\ University of South Bohemia, České Budějovice, Czech Republic \\ ${ }^{3}$ Department of Management, Faculty of Economics, \\ University of South Bohemia, České Budějovice, Czech Republic
}

Received 10 September 2019; accepted 18 August 2020

\begin{abstract}
The goal of this paper is to investigate the impact of technology investments on production efficiency in manufacturing companies and how different these relationships are for low-technology and high-technology companies. The empirical part was based on the analysis of 2,848 large, small and medium-sized Czech companies by using Bayesian networks (BNs). The results show that technological investments have the greatest positive impact on the growth of labour productivity and on a decline in labour intensity in low technology enterprises. The technological investments have a positive impact on labour productivity growth in high-technology enterprises, but at the same time, the technological investments have an impact on the increase of labour intensity. On the contrary, the influence of investment growth was insignificant on the indicators of material and services intensity. Technologically intensive investments have a different impact on small, mediumsized and on large enterprises. The reaction of large companies depends on the category of technology intensity in contrast to small and medium-size enterprises.
\end{abstract}

Keywords: performance, technology investment, Bayesian networks, manufacturing, technological intensity, labour productivity.

JEL Classification: D24, L25, O33.

\section{Introduction}

Industry is an important part of the economy of the European Union and it must continually invest in new technologies and innovations in order to maintain its international competitiveness. Annually, it generates about $19.63 \%$ of the gross added value of the EU economy (Eurostat, 2019) compared to $14.72 \%$ in the USA (OECD stat., 2019). Greater

*Corresponding author. E-mail: novotna@ef.jcu.cz

Copyright (c) 2020 The Author(s). Published by Vilnius Gediminas Technical University

This is an Open Access article distributed under the terms of the Creative Commons Attribution License (http://creativecommons. org/licenses/by/4.0/), which permits unrestricted use, distribution, and reproduction in any medium, provided the original author and source are credited. 
global competition in industry will mainly affect EU countries with a strong industrial base, including large industrial countries such as Germany, and small industry-oriented states such as the Czech Republic, which this article is focused on. Since its formation in 1918, the Czech Republic has been a country with a large industrial share of the economy in terms of economic performance and employment. The share of industry in the creation of gross value added (GVA) for the whole of the Czech economy is about 27\% (Eurostat, 2019). This share has not changed in the short and long time period (Kraftova et al., 2011).

Globalization and rapid technological advances have caused considerable changes in the world economy. On the one hand, there are low cost economies such as China or India and, on the other, there are economies based on innovation (Grubicka \& Matuska, 2015) such as the United States or South Korea. An important part in increasing the competitiveness of businesses in European industry is related to investment (Dosi et al., 2015). The investments that companies will realize will also have an important impact on the performance of the entire industry. The investment orientation significantly influences the new technological paradigm that transforms the production system (Freeman \& Perez, 1988). Countries with high technological investments in ICT are able to increase the growth rate of the total factor productivity (Hawash \& Lang, 2020).

The influence of technological investments on the efficiency of utilization of human resources in companies has been analysed by Haller (2014), Chung (2018), and Baumann and Kritikos (2016). The previous empirical studies assessing the impact of company investment on labour productivity were focused on the investments into information and communication technologies (ICT) (Thatcher \& Oliver, 2001; Becchetti et al., 2003; Chung, 2018), investment into research and development (R\&D) (Aldieri et al., 2008; Baumann \& Kritikos, 2016) and foreign direct investment (FDI) (Egger \& Pfaffermayr, 2001; Girma et al., 2001; Haller, 2014). Chung (2018) has shown that companies' technology investment in ICT contributed to labour productivity growth in the South Korean economy. Baumann and Kritikos (2016) examined the link between investments in R\&D, innovation and labour productivity according company size. They found that the link between companies investments in R\&D and labour productivity in micro sized companies does not differ largely from larger ones. In another study, Borin and Mancini (2016) measured the effects of foreign direct investment on the performance of Italian companies. They found an effect on the growth rate of labour productivity only in short time horizons and pointed out the importance of the given type of economic sector.

A company's investments in technologies have an impact on their labour productivity (Driffield \& Temouri, 2014), but a significant impact on the multiplier effect of investment depends on the kind of industry. One of the ways to divide companies into an industry is according to their technological intensity, which has an impact on the investment activity of companies (Zawislak et al., 2018). Previous studies have examined the impact of technology investment on business efficiency but have not dealt with the differences in companies' responses according to their technological intensity in the context of their size.

The aim of this paper is to examine the impact of technology investments on companies' production efficiency in manufacturing, mostly onto labour productivity and cost ratio. Economic activity (technological intensity) and size of a company are also consid- 
ered. This study is expected to contribute to economic theory in the field of identifying the probability of the effect of technological investments on changing the efficiency of production factors in different groups of enterprises, both by size and technological intensity. From the economic policy point of view, it is important to know which companies need to be encouraged to increase innovative investment activity. The findings of the presented analysis are important for investors considering manufacturing as a part of their investment portfolios and for policymakers. The use of Bayesian networks (BNs) sheds new light on the consideration of the technology investment effect on companies and this is a different approach to standard analyses. The study can be considered as extensive from an international perspective.

The paper is structured as follows: The theory of companies' investment, competitiveness and efficiency are briefly analysed in the first part. The second part shows the data, the empirical framework and the methodological procedure. The third part introduces the results of the $\mathrm{BN}$ model used to analyse the impact of technology investment on the company's production efficiency and which takes into account the dependencies between selected indicators. This part evaluates changes in the probabilities of the observed economic indicators as a result of technological investments. The differences in the results of companies are assessed according to their technological intensity and size. The fourth part summarizes the analysed results and points out an area for further research.

\section{Literature review}

The basis for measuring companies' efficiency of economics is the production function. The neoclassical production function takes the form $Y=F(K, L, T)$ where $Y$ is the output produced. Capital $(K)$ presents the durable physical inputs. The second input is labour $(L)$ and it represents the inputs connected with people. The third input is the level of technology $(T)$ (Barro \& Sala-i-Martin, 2004). The Solow model shows that the growth of resources depends on productive investment in gross fixed capital formation. In this model, output (GDP or Value Added) per worked hour is labour productivity. The size of labour productivity depends on the growth rate of capital accumulation per hour. According to Takahashi (2012), the growth effect of capital depends on which type of capital is enhanced. The modern theory of economic growth states that there is a strong link between investments in research and development (R \& D) and the economic growth of a state (Romer, 1990) or regions (Leitmanova \& Krutina, 2009), a sector (Ulku, 2007) and companies (Wakelin, 2001).

The impact of investment on the production efficiency factor (productivity) is analysed in diverse theoretical and empirical analyses or studies. The choice of the productivity indicator depends on the purpose of measurement and on the availability of data. The most frequent indicators are labour productivity and total factor productivity. Labour productivity is related to the efficiency of production. Labour productivity is the ratio of the value added to the full-time labour working in companies (Preenen et al., 2015) or gross value added and total employment for countries (Basile \& De Benedictis, 2008). There are two sources of labour productivity growth: technical progress and growth of capital-labour $(K-L)$ ratio (Guest, 2011) by growth of investment. Empirical analyses focused on the impact of invest- 
ment on labour productivity from the macro perspective or micro (companies) perspective. Filippetti and Peyrache (2015) highlight that the growth of labour productivity in EU regions is mainly driven by capital accumulation (investments). Stundziene and Saboniene (2019) investigated if the investment in tangible assets improves labour productivity in the European manufacturing industry. This research confirms a positive relation between labour productivity and investment in tangible assets for the EU manufacturing. They pointed out the impact that various types of investment have in labour productivity. The total factor productivity includes productivity not only available inputs (capital,labour) but also on other factors of production. Measuring TFP requires data on other inputs as well, such as physical and human capital, which are not commonly available (Beugelsdijk et al., 2018). In economic theory, TFP is measured indirectly. It is the output growth not explicable by changes in the amount of inputs (often referred to as Solow residual). In the economic practice, TFP is measured by productivity indexes or productivity indicators (Malmquist productivity index, HicksMoorsteen productivity index and Luenberger productivity indicator, Törnqvist productivity index, Fisher productivity index, Bennet-Bowley productivity indicator or TFP (based on economic value added)). The authors chose the labour productivity indicator to measure the production efficiency due to the different approaches to calculating TFP and the difficulty of calculating TFP, especially for small and medium-sized enterprises. There are considerable methodological issues in calculating TFP. Van Beveren (2012) examined the estimation of TFP only for the food and beverages sector. This paper is more detailed and it contains different sectors within manufacturing. The innovation effects of the companies' investment intensity on TFP were statistically not clear or robust (Tello, 2015). Another reason for this paper creation is that if the article's outputs were used for economic policy to support innovative activities related to corporate investments in technology, the effectiveness of support can be more easily verified through the labour productivity indicator. In the competitive globalized world, labour productivity is one of the key factors of success. A survey conducted in the Czech Republic showed that $94 \%$ of companies evaluate their own productivity but only $74 \%$ of them evaluate only labour productivity (Machek \& Hnilica, 2012). The company's investments into technology are a prerequisite for long-term growth and business development. Investments are one of the most important determinants of a company's future ability to enter a market and compete. Tangible investments have big importance for companies, but intangible investments are also no less important according to Seo and Kim (2020) companies study. Investment direction is also important. Some empirical analyses (Parisi et al., 2006; Gibson \& Naquin, 2011) proved that investment in research and development and investment in fixed capital assets when introducing innovation have a positive impact on productivity and economic growth. Investing in innovation becomes crucial for maintaining the competitiveness of companies. The growth of innovation in companies has an impact on the growth of production in all sectors (Ulku, 2007). In industry, innovation is directed to intelligent manufacturing (Jardim-Goncalves et al., 2017; Poor \& Basl, 2019), which is often referred to as Industry 4.0. New technologies are directed to distributed systems in this vision and work with methods of auto-optimization, intelligent worker support, self-diagnosis, machine perception, and self-configuring (Stock \& Seliger, 2016; MacDougall, 2014). External and 
internal factors influence the implementation of technologically demanding investments and innovations in an enterprise. However, it may deal with many barriers, significantly affecting the rate of implementation of changes resulting from the investments and also the extent of possible investments.

Industry growth is clearly linked to the concept of competitiveness in market economies. As defined by the OECD (OECD/Eurostat, 2005), competitiveness is the ability of industry to generate a high level of income from the production factors and a relatively high level of their use at a sustainable level while being exposed to international competition. The Czech Republic is one of the states whose competitive advantage is being driven by innovation. The share of technologically advanced sectors in the overall production of the economy is increasing (Kraft \& Kraftova, 2012). In different sectors, there are structural changes in the production of products and services with higher technological excellence and added value.

\section{Materials and methods}

\subsection{Aim and sample}

The paper focuses on an analysis of the influence of technology investments in manufacturing on a company's efficiency. The possible investment impacts on a company's efficiency are found out as probabilities with which the values of the sample intensive indicators would range within certain values. To analyse the relationships and probabilities, the Bayesian network (BNs) model is used. The authors attempted to model the relationships between individual variables, while the direction of dependence and interrelations was not an obvious priority for all of them. Due to this limitation, the authors implemented only partially the knowledge about the structure of interrelations. For these reasons, we use the Bayesian approach here, more precisely, Bayes nets methodology that allows us to uncover the remaining structure (interrelations) from the data. Attention is focused on innovations that may necessitate high-tech investments. The main part of the analysis is based on the audited financial statements from a selected 2,848 manufacturing companies in 2016 from the company database Albertina. The companies were selected according to their structure by technological intensity that corresponds to the structure of the manufacturing industry in Czech Republic. The companies were divided by their size and technological intensity. Companies were chosen so as to reach a compromise between the depth of analysis and a generalization of results. Several tests of the homogeneity of multinomial distribution were done with the aim of testing compliance with the distribution of output (Labour productivity), c.l.ratio (The capital labour ratio), maei (Material and energy intensity), si (Service intensity), li (Labour intensity) in Czech manufacturing. These tests were not significant and for the sake of brevity, we did not provide these results.

According to a number of studies (Driffield \& Temouri, 2014; Mařík et al., 2016), technological investment mostly influences labour productivity, output, with an average growth of 30-35\% supposed within 5 years (Geissbauer et al., 2016). Therefore, this indicator in the BNs model was chosen as an output. At the same time, the level and magnitude of the change in labour productivity (share of Revenues and Personnel expenses) is affected by a number of factors; the paper deals with six factors. The first is classified by NACE economic activity, 
based on Eurostat methodology. The enterprises were sorted into four categories. Eurostat uses the following aggregation of the manufacturing industry according to technological intensity and based on NACE Rev. 2 at 2-digit level for compiling aggregates related to hightechnology (HT), medium-high-technology (M-HT), medium-low-technology (M-LT) and low-technology (LT) (Eurostat, n.d.).

The second factor influencing labour productivity - output, is the size of the enterprise. We used the classification by EU Commission Recommendation 2003/361/ESES based on the number of employees, turnover and balance sheet total. Empirically, the effect of the size of an economic entity on the level of labour productivity was confirmed by statistical analysis (ANOVA Analysis) from 2016 data in the Czech Republic. A statistically significant effect of this factor has been demonstrated (Trexima, 2018). A positive relationship between company size and labour productivity has also been found in a study by Leung et al. (2008).

The other three considered factors no longer take the form of categorical variables, but they are relative ratios that show causality with labour productivity. The third factor is - the capital labour ratio (c.l. ratio), which expresses how many CZK of fixed assets is worth $1 \mathrm{CZK}$ of labour costs (the ratio of the sum of tangible and intangible fixed assets and Personnel expenses). The realization of technological investments affects the size of the capital/labour ratio. A study by Río and Lores (2019) shows that the growth of capital-augmenting led to a decrease of the capital productivity in the US and to a steady increase in the labour productivity. The results of a study by Stundziene and Saboniene (2019) shows that a $1 \%$ increase in gross investment in tangible goods per person employed in manufacturing has a $0.0373 \%$ long-run effect on labour productivity. We assume that the higher the value of the capitallabour ratio, the higher is the level of labour productivity. The assumption is subsequently verified by BNs analysis.

Material and energy intensity - referred to as maei (Consumption of material and energy/ Production) - is the fourth factor of the model. This indicator informs us about how much material and energy was spent on one CZK. The indicator is considered (Wolter et al., 2015) significant in introducing new technologies.

The fifth factor is service intensity - referred to as si (Services/Production). In implementing investment (both high-tech and capital intensive) with the efficiency on labour productivity, there is a prerequisite that service, maintenance, security and know would be provided by outsourcing.

Labour intensity - referred to as $l i$ - is the sixth factor (Personnel expenses/Total cost). A higher share of labour factor cost is linked to lower labour productivity. This factor significantly influences the output. Table 1 provides a definition of the indicators and descriptive statistics found on the set of 2848 enterprises.

Table 2 describes primary data from the enterprises in manufacturing in 2016. A majority of enterprises (64\%) were classified by EC methodology as small and medium-sized (SMEs). $34 \%$ were of large enterprises. Classified by the technological intensity based on the Eurostat methodology, there was a majority of M-LT and LT enterprises. Regarding HT and M-HT, there was a majority of large enterprises, as supposed. In the case of such enterprises, the economic characteristics used in the BNs model as output and inputs were further analysed. The mean values of these intensive ratios are shown in Table 2. 
Table 1. Used indicators and summary statistics (source: authors' calculation)

\begin{tabular}{|l|l|l|c|c|c|}
\hline $\begin{array}{c}\text { Short- } \\
\text { cut }\end{array}$ & \multicolumn{1}{|c|}{ Indicator name } & \multicolumn{1}{|c|}{ Definition } & Average & Median & $\begin{array}{c}\text { Standard } \\
\text { deviation }\end{array}$ \\
\hline output & $\begin{array}{l}\text { Labour productivity in } \\
\text { CZK }\end{array}$ & $\begin{array}{l}\text { (Revenues from the sale of } \\
\text { own products and services } \\
\text { and from sold goods)/ } \\
\text { Personnel cost }\end{array}$ & 8.016 & 5.020 & 14.523 \\
\hline c.l. ratio & $\begin{array}{l}\text { The capital labour ratio } \\
\text { in CZK }\end{array}$ & $\begin{array}{l}\text { (Tangible + intangible fixed } \\
\text { assets)/Personnel expenses }\end{array}$ & 2.827 & 1.313 & 8.245 \\
\hline maei & $\begin{array}{l}\text { Material and energy } \\
\text { intensity in CZK }\end{array}$ & $\begin{array}{l}\text { Consumption of material and } \\
\text { energy/Production }\end{array}$ & 0.879 & 0.476 & 7.007 \\
\hline si & Service intensity in CZK & Services/Production & 10.105 & 0.155 & 162.558 \\
\hline$l i$ & Labour intensity in CZK & Personnel expenses/Total cost & 0.225 & 0.200 & 0.140 \\
\hline
\end{tabular}

Note: Number of observations: 2848, Data from BALANCE SHEET and PROFIT/LOSS ACCOUNT.

Table 2. Primary data by technological intensity and by size (source: authors' calculation)

\begin{tabular}{|c|c|c|c|c|c|c|c|c|}
\hline & & \multicolumn{2}{|c|}{ Frequency } & \multirow{2}{*}{$\begin{array}{l}\text { output in } \\
\text { CZK }\end{array}$} & \multirow{2}{*}{$\begin{array}{l}\text { c.l.ratio } \\
\text { in CZK }\end{array}$} & \multirow{2}{*}{$\begin{array}{c}\text { maei in } \\
\mathrm{CZK}\end{array}$} & \multirow{2}{*}{$\begin{array}{c}s i \\
\text { in }{ }^{\mathrm{CZK}}\end{array}$} & \multirow{2}{*}{$\stackrel{l i}{\text { in } \mathrm{CZK}}$} \\
\hline & & Absolute & Relative in \% & & & & & \\
\hline \multirow{3}{*}{ HT } & Total & 81 & 2.84 & 25.16 & 2.04 & 0.89 & 0.03 & 0.04 \\
\hline & SMEs & 43 & 53.09 & 3.72 & 0.98 & 0.41 & 0.56 & 0.28 \\
\hline & Large & 38 & 46.91 & 26.83 & 2.11 & 0.90 & 0.02 & 0.04 \\
\hline \multirow{3}{*}{ M-HT } & Total & 753 & 26.44 & 10.83 & 2.66 & 0.70 & 0.07 & 0.09 \\
\hline & SMEs & 384 & 51.00 & 4.25 & 1.40 & 0.45 & 0.97 & 0.23 \\
\hline & Large & 369 & 49.00 & 11.35 & 2.75 & 0.71 & 0.05 & 0.09 \\
\hline \multirow{3}{*}{ M-LT } & Total & 1228 & 43.12 & 6.71 & 2.21 & 0.51 & 0.21 & 0.15 \\
\hline & SMEs & 843 & 68.65 & 4.27 & 1.53 & 0.42 & 1.23 & 0.24 \\
\hline & Large & 385 & 31.35 & 7.17 & 2.33 & 0.52 & 0.10 & 0.14 \\
\hline \multirow{3}{*}{ LT } & Total & 786 & 27.60 & 9.33 & 4.27 & 0.60 & 0.21 & 0.11 \\
\hline & SMEs & 562 & 71.50 & 4.41 & 1.63 & 0.52 & 1.58 & 0.22 \\
\hline & Large & 224 & 28.50 & 10.53 & 4.92 & 0.61 & 0.08 & 0.09 \\
\hline \multirow{3}{*}{ Total } & Total & 2848 & 100.00 & 9.78 & 2.74 & 0.66 & 0.12 & 0.10 \\
\hline & SMEs & 1832 & 64.33 & 4.29 & 1.51 & 0.45 & 1.24 & 0.23 \\
\hline & Large & 1016 & 35.67 & 10.56 & 2.92 & 0.68 & 0.06 & 0.09 \\
\hline
\end{tabular}

The output level depends on several factors, but it is clear from Table 2 that the technological intensity of enterprises and the size of enterprises have a significant impact on output (i.e. the more technologically, more intensive the economic activity, the higher is the output). This outcome coincides with T. Kijek and A. Kijek (2019), who show in their study that the medium and high technology companies are probably more efficient in exploiting opportunities from investment (ICT investments) than low technology firms. The primary data analysis also revealed a considerable difference between the indicators' level depending on the size. According to a study by Tello (2017), firm size and investment intensity 
are key determinants in increasing technological and non-technological innovation outputs and labour productivity across manufacturing sectors. Material and energy intensity (maei) is the highest in HT mostly large enterprises. On the contrary, service intensity $(s i)$ is the lowest in such enterprises, proving that the majority of activities are done within the enterprise, with a minimum provided by outsourcing. The highest service intensity $(s i)$ is related to M-LT and LT enterprises, mostly small and medium-sized. Labour intensity (li) is highest for M-LTs. In all categories, the li score reaches the highest for SMEs, where personnel costs account for about a quarter of total costs. On the other hand, large enterprises, for example, in the HT category, amounted to only $4 \%$ of the personnel costs in total costs.

\subsection{Transformation of the data and Bayesian networks}

For discretization purpose, we used Hartemink's information-preserving algoritm (Hartemink, 2001) for more details, please see (Scutari \& Denis, 2014). We used Bayesian networks (BNs) because of its ability to integrate data and a prior knowledge form different sources. Furthermore, visualization of BN enables better understanding of model structure. The BN model (Scutari, 2017) was built using the programming language $\mathrm{R}$. These packages provide a free implementation of some BN structure and parameter learning algorithms. Before we proceed to own BN structure learning we can say that this algorithm iterates over the variables and collapses, for each of them, the pair of adjacent intervals that minimize the loss of pairwise mutual information. This algorithm tries to reflect the dependence structure of the original data better than either quantile or interval discretization would allow (Scutari \& Denis, 2014; Scutari, 2010).

BNs are increasingly being used to model complex systems, in order to utilize multiple information and different components. From a mathematical point of view, we can describe BN as graphical structure $G=(V, A)$ which forms a discrete acyclic graph (DAG) where $V$ is the set of nodes and $A$ is the arcs set (Koller \& Friedman, 2009). The nodes represent variables whereas arcs in $\mathrm{BN}$ represent the causal or influential relationship between them. In a $\mathrm{BN}$, each node has an associated Node Probability Table. The DAG structure defines a so-called factorization of the joint probability distribution of $V=\left\{X_{1}, \ldots, X_{v}\right\}$ into a set of local probability distributions, one for each variable. The factorization use so-called Markov property of Bayesian networks, which states that every random variable $X_{i}$ directly depends only on its parents. More exact information about technical issues could be found for example (Pearl, 1988; Nagarajan et al., 2013). In case of discrete variables Eq. (1):

$$
P\left(X_{1}, X_{2}, . ., X_{v}\right)=\prod_{i=1}^{v} P\left(X_{i} \mid \text { parents }\left(X_{i}\right)\right) .
$$

For BN structure learning, we used the so-called Hill-Climbing algorithm, see (Scutari, 2010), with an implied topology restriction. In other words, we used the so-called "blacklist", e.g. set of causal linkages, which are not allowed to be present in our model. On the other hand, we imposed another set "whitelist" e.g. a set of causal linkages, which imply our prior knowledge about dependence structure. To access a goodness of suitability, we used Bayes Information Criterion (BIC) score. All computations were carried out using the programming environment R 3.3.3. 


\section{Results and discussion}

\subsection{Firm's production efficiency (results of BNs)}

First, we have to propose a structure for out BN. We used a combined approach and implement our knowledge with information. The strength and the direction of relations, based on bootstrap $R=200$ (a hill-climbing algorithm). After converging the hill-climbing algorithm with restriction implemented by blacklist and whitelist, we obtained $\mathrm{BN}$, which could be described by the following product of conditional probabilities:

$$
\begin{gathered}
P(\text { sector, } \text { maei, } \text { li, size, c.1.ratio, output, } s i)=P(\text { sector }) \times P(\text { maei } \mid \text { sector }) \times \\
P(l i \mid \text { maei }) \times P(\text { size } \mid \text { sector, } l i) \times P(\text { c.l.ratio } \mid \text { sector, } l i) \times \\
P(\text { output } \mid \text { sector, size, c.l.ratio, maei }) \times P(\text { si } \mid \text { sector, size }) .
\end{gathered}
$$

This $\mathrm{BN}$ reached $\mathrm{BIC}=-26$ 764.67. Corresponding DAG structure is graphically depicted in Figure 1. Our derived Bayesian net could be briefly characterized as a network with 7 nodes, 12 arcs ( 0 undirected, 12 directed) with an average Markov blanket size equal to 4.57 and the average neighbourhood size to 3.43 .

Using BNs, causal dependencies were detected (Figure 1). Considering these dependencies and mainly the causality directions, it is clear that the sector category (determined by the technological intensity of economic activities) affects all sample variables. This is confirmed by a study by Heidenreich (2009) which shows that the category of enterprise according to technological intensity plays an important role in the impact of technology investments. The capital labour ratio (c.l.ratio) is influenced by both the sector and the share of personnel costs in the total costs (li), which in turn is related to the economic activity of the enterprise (i.e. with the sector). The capital labour ratio, at the same time, significantly affects the labour productivity (output).

On the basis of the BNs, the predicted dependencies between selected indicators were practically verified.

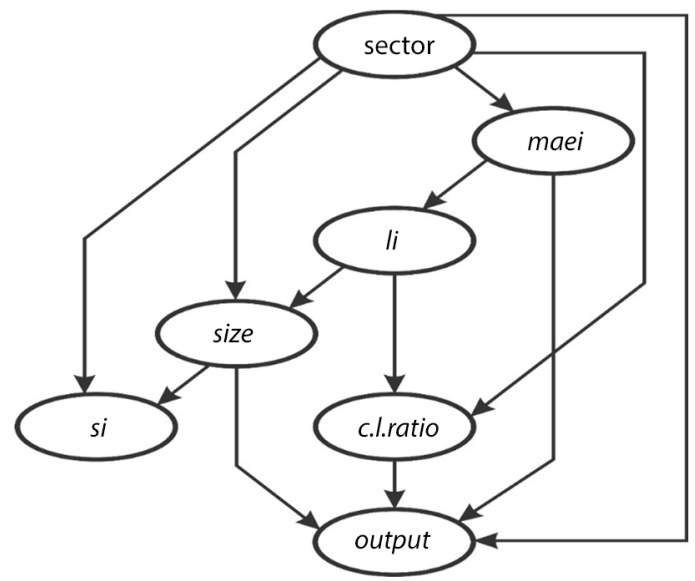

Note: maei - material and energy intensity, $l i$ - labour intensity, c.l.ratio - capital labour ratio, $s i$ - service intensity.

Figure 1. Resulting Bayesian net 
As our approach uses BNS Model, it differs from other approaches which used a correlation and regression analysis (Rüßmann et al., 2015) or a survey (Geissbauer et al., 2016).

Manufacturing companies today must withstand the increasing global competition on products quality or quantity, companies productivity and production costs. One way to solve this situation is a progressive implementation of technological investment projects into production (Brettel et al., 2014). The economic performance will then increase the capital labour (c.l.ratio). The next step of BNs analysis was to outline a possible reaction of variables (probabilities and intervals of variables) if the variable c.l.ratio changes, for all sectors and sizes of the enterprises. Different scenarios are based on the average value of the c.l.ratio variable in different sectors and size categories.

The study of Heidenreich (2009) confirmed this and showed that the category of enterprises, according to the technological intensity, plays an important role in the impact of technology investments. According to Tello (2017), firm size is a key determinant for decisions on investment activities.

The aim was to examine the probability of changing the remaining variables if there is a shift in the capital labour ratio (i.e., the realization of investments will increase the ratio of long-term assets to CZK 1 of personnel costs) for different types of enterprises. At first, it is necessary to describe the current state (Table 3 ).

The data analysis revealed (Table 3 ) that if e.g. c.l.ratio of HT small and medium-sized enterprises ranges from 0.02 to 1.05 , the output (in CZK per $1 \mathrm{CZK}$ of personnel costs) will range from 2.5 to 4.5 , with the probability of 0.49 ; the maei (material and energy intensity) will range from 0.14 to 0.42 , with the probability of 0.49 ; service intensity $(s i)$ will range from 0.09 to 0.37 with the probability of 0.37 and labour intensity ( $l i$ ) will range from 0.22 to 0.4 , with the probability of 0.51 .

Table 3. Probabilities and interval of indicator (source: authors' calculation)

\begin{tabular}{|c|c|c|c|c|c|c|c|c|}
\hline $\begin{array}{l}\text { Cate- } \\
\text { gory }\end{array}$ & $\begin{array}{l}\text { c.l.ratio } \\
\text { Interval in } \\
\text { CZK }\end{array}$ & \multicolumn{2}{|c|}{$\begin{array}{c}\text { output } \\
\text { (Interval } \\
\text { in CZK) } \\
\text { probability }\end{array}$} & \multicolumn{2}{|c|}{$\begin{array}{c}\text { maei } \\
\text { (Interval in } \\
\text { CZK) } \\
\text { probability }\end{array}$} & \multicolumn{2}{|c|}{$\begin{array}{c}s i \\
\text { (Interval in } \\
\text { CZK) } \\
\text { probability }\end{array}$} & $\begin{array}{c}i \\
\text { (Interval in } \\
\text { CZK) } \\
\text { probability }\end{array}$ \\
\hline \multicolumn{9}{|c|}{ SMEs } \\
\hline $\mathrm{HT}$ & $(0.02,1.05)$ & $(2.5,4.5]$ & 0.49 & $(0.14,0.42]$ & 0.49 & $(0.09,0.37)$ & 0.37 & $(0.22,0.4] \quad 0.51$ \\
\hline M-HT & $(1.05,1.7)$ & $(2.52,4.5]$ & 0.40 & $(0.42,0.59]$ & 0.34 & $(0.37,32.3]$ & 0.39 & $(0.22,0.4] \quad 0.40$ \\
\hline M-LT & $(1.05,1.7)$ & $(2.52,4.5]$ & 0.43 & $(0.42,0.59]$ & 0.31 & $(0.09,0.37]$ & 0.32 & $(0.22,0.4] \quad 0.46$ \\
\hline LT & $(1.05,1.7)$ & $(2.52,4.5]$ & 0.44 & $(0.42,0.59]$ & 0.35 & $(0.37,32.3]$ & 0.43 & $(0.22,0.4] \quad 0.49$ \\
\hline \multicolumn{9}{|c|}{ Large } \\
\hline HT & $(1.7,3.95)$ & $(2.5,4.5)$ & 0.32 & $(0.73,199]$ & 0.29 & $\begin{array}{l}(0.01,0.09) \\
(0.09,0.37)\end{array}$ & $\begin{array}{l}0.34 \\
0.34\end{array}$ & $(0.06,0.14] 0.49$ \\
\hline M-HT & $(1.7,3.95)$ & $(7.5,16.9]$ & 0.40 & $(0.59,0.73]$ & 0.29 & $(0.01,0.09]$ & 0.44 & $(0.06,0.14] 0.46$ \\
\hline M-LT & $(1.7,3.95)$ & $(4.5,7.54]$ & 0.47 & $(0.42,0.59]$ & 0.33 & $(0.01,0.09]$ & 0.49 & $(0.14,0.22] 0.39$ \\
\hline LT & $(3.95,16)$ & $(7.5,16.9]$ & 0.54 & $(0.73,199]$ & 0.34 & $(0.01,0.09]$ & 0.42 & $(0.06,0.14] 0.48$ \\
\hline
\end{tabular}


Table 3 shows that SMEs are more likely to include individual indicators in the appropriate intervals. For large enterprises, the significant probabilities are spread over several intervals. Supposing that the enterprises may gradually realize technologically intensive investments that cause a shift in c.l.ratio for each category and size group to the next interval (i.e., the capital labour ratio is increased), then this situation can be modelled using Bayesian networks and there are also changes in the probabilities of the respective value intervals of the other sample indicators, and a change of the intervals with the highest achievable probability (Table 4).

Table 4. Differences of probabilities after the c.l.ratio shift in selected indicators (source: authors' calculation)

\begin{tabular}{|c|c|c|c|c|c|c|c|c|}
\hline $\begin{array}{l}\text { Cate- } \\
\text { gory }\end{array}$ & $\begin{array}{l}\text { c.l.ratio } \\
\text { Interval in } \\
\quad \text { CZK }\end{array}$ & \multicolumn{2}{|c|}{$\begin{array}{c}\text { output } \\
\text { (Interval in CZK) } \\
\text { probability }\end{array}$} & \multicolumn{2}{|c|}{$\begin{array}{c}\text { maei } \\
\text { (Interval in CZK) } \\
\text { probability }\end{array}$} & \multicolumn{2}{|c|}{$\begin{array}{c}s i \\
\text { (Interval in CZK) } \\
\text { probability }\end{array}$} & $\begin{array}{c}\text { li } \\
\text { (Interval in CZK) } \\
\text { probability }\end{array}$ \\
\hline \multicolumn{9}{|c|}{ SMEs } \\
\hline HT & $(1.05,1.7)$ & $(4.5,7.54]$ & 0.12 & $(0.14,0.42)$ & -0.01 & $(0.09,0.37)$ & 0.00 & $(0.14,0.22] \quad 0.16$ \\
\hline M-HT & $(1.7,3.95)$ & $(4.5,7.54]$ & 0.10 & $(0.42,0.59]$ & -0.02 & $(0.37,32.3]$ & 0.00 & $(0.06,0.14] \quad 0.10$ \\
\hline M-LT & $(1.7,3.95)$ & $(2.52,4.5]$ & $-0,06$ & $(0.42,0.59]$ & -0.01 & $(0.09,0.37]$ & 0.00 & $\begin{array}{lll} & 0.22,0.4] & -0.04 \\
\end{array}$ \\
\hline LT & $(1.7,3.95)$ & $(7.5,16.9]$ & 0.13 & $\begin{array}{l}(0.14,0.42] \\
(0.73,199]\end{array}$ & $\begin{array}{r}-0.07 \\
0.07\end{array}$ & $(0.37,32.3]$ & 0.00 & $\begin{array}{lr}(0.22,0.4] & -0.18 \\
(0.06,0.14] & 0.17 \\
\end{array}$ \\
\hline \multicolumn{9}{|c|}{ Large } \\
\hline HT & $(3.95,16)$ & $(7.5,16.9)$ & 0.17 & $(0.14,0.42]$ & 0.06 & $\begin{array}{l}(0.01,0.09) \\
(0.09,0.37)\end{array}$ & $\begin{array}{l}0.00 \\
0.00\end{array}$ & $(0.22,0.4]$ \\
\hline M-HT & $(3.95,16)$ & $(16.9,363]$ & 0.19 & $(0.73,199]$ & 0.08 & $(0.01,0.09]$ & 0.00 & $(0.00,0.06] \quad 0.18$ \\
\hline M-LT & $(3.95,16)$ & $(16.9,363]$ & 0.19 & $(0.73,199]$ & 0.07 & $(0.01,0.09]$ & 0.00 & $(0.00,0.06] \quad 0.16$ \\
\hline LT & $(16,306)$ & $(4.5,7.54]$ & 0.21 & $(0.73,199]$ & -0.08 & $(0.01,0.09]$ & 0.00 & $(0.00,0.06]-0.13$ \\
\hline
\end{tabular}

Different development scenarios of the indicators were modelled by shifting the value interval of c.l.ratio in relation to possible investments. It was proved that this shift does not bring almost any change in the probability or in the shift of the interval with the highest probability of acquiring the values of the indicator of service intensity $(s i)$, even in different categories, i.e. for technological intensity of industrial enterprises and for different size groups. This result differs from the study of Birkel et al. (2019) which identifies the risks that arise within the technology investment in Industry 4.0. They expect an increase in external service costs. This difference can be explained by Birkel's et al. (2019) orientation on ICT services in the context of investment in Industry 4.0. Many studies (Bartodziej, 2017 or Bahrin et al., 2016) mentioned that technology investments are linked to the increase in service intensity, which was not confirmed by our study.

Only minor changes occur in the probability of reaching the maei value. For SMEs, the interval of the maei remains unchanged, but the greatest probability difference is found for LT enterprises, where the maei will decrease the probability of a shift to the interval $(0.14$, 0.42 ] and the probability that maei will move in a higher value interval $(0.73 .199]$ is increased. This means that for LT enterprises the change in the capital labour ratio can cause 
a change in material intensity (it is positive, i.e. its reduction, but also negative especially for LT enterprises, which means an increase in material intensity).

The most significant changes in the implementation of technologically intensive investments are assumed in the output indicator (labour productivity), especially for large enterprises, where the change in the technical equipment of labour will most likely mean a shift in the output values (see also Figures 2 and 3). The conclusion that technology investment improves labour productivity in large firms is not consistent with that established by Badescu and Garcés-Ayerbe (2009), which analysed the impact of investments in information technologies on the productivity of Spanish firms. On the other hand, Tambe and Hitt (2011) in their study confirmed the greater impact of technology IT investments on the productivity of large enterprises. The expectation of authors Geissbauer et al. (2016) and Rüßmann et al. (2015), dealing with the results of technological investment implementation (nowdays Industry 4.0), are too optimistic as seen in the analyses carried out in this paper. Van Ark (2016) has pointed out the possibility of paradox productivity too. He has analysed this effect of technology investments in the United States, the United Kingdom and Germany.

In this context, T. Kijek and A. Kijek (2019) point out that enterprises that do not face human capital constraints also have higher productivity. Medium-sized and large companies, which also employ a large number of workers, are able to better adjust the structure of workers when implementing investments than small firms. In line with these results, the importance of workers' human capital in explaining productivity differences is also stressed (Syverson, 2011). Ramírez et al. (2019) suggest that human capital has a causal effect on research and development (R\&D), investment decisions, the innovation behaviour of the firm, and increases the labour productivity of the firm.

A great importance is also shown for a shift of c.l.ratio to labour intensity (li). With this indicator, the interval is most likely to shift in a positive direction, i.e. the probability of reducing the share of personnel costs in overall cost is increased. In large HT enterprises, the greatest difference of probabilities was found in the interval $(0.22,0.4]$. There is a probability of increased share of personnel cost in total cost, due to increased requirements for a skilled workforce (change in the structure of employed people). On the other hand, it is necessary to point out the effectiveness of the workforce. Spiesia (2012) in his study, pointed out that the value added elasticity of labour is significantly higher in high-technology companies than in non-high-technology companies. In HT small and medium-size enterprises, there is the largest difference of probabilities in the interval $(0.14,0.22]$. It means the probability of a lower share of personnel cost in total cost is increased. For these enterprises, this may mean that there is actually a saving of workers, i.e. the share of personnel costs. Müller et al. (2018) have found similar results from the study that examines the impacts of new technology investments (Industry 4.0) on German companies. For a large M-HT and L-HT enterprise, the most increased probability is reported for li values in the lowest interval of values (it also means increasing the probability of saving the share of personnel costs in total costs). To the contrary, in large LT enterprises, the probability that the values of the li indicator will range in the lowest interval significantly decreases which can mean there is a risk to the future (Blažková \& Dvoulety, 2019). 


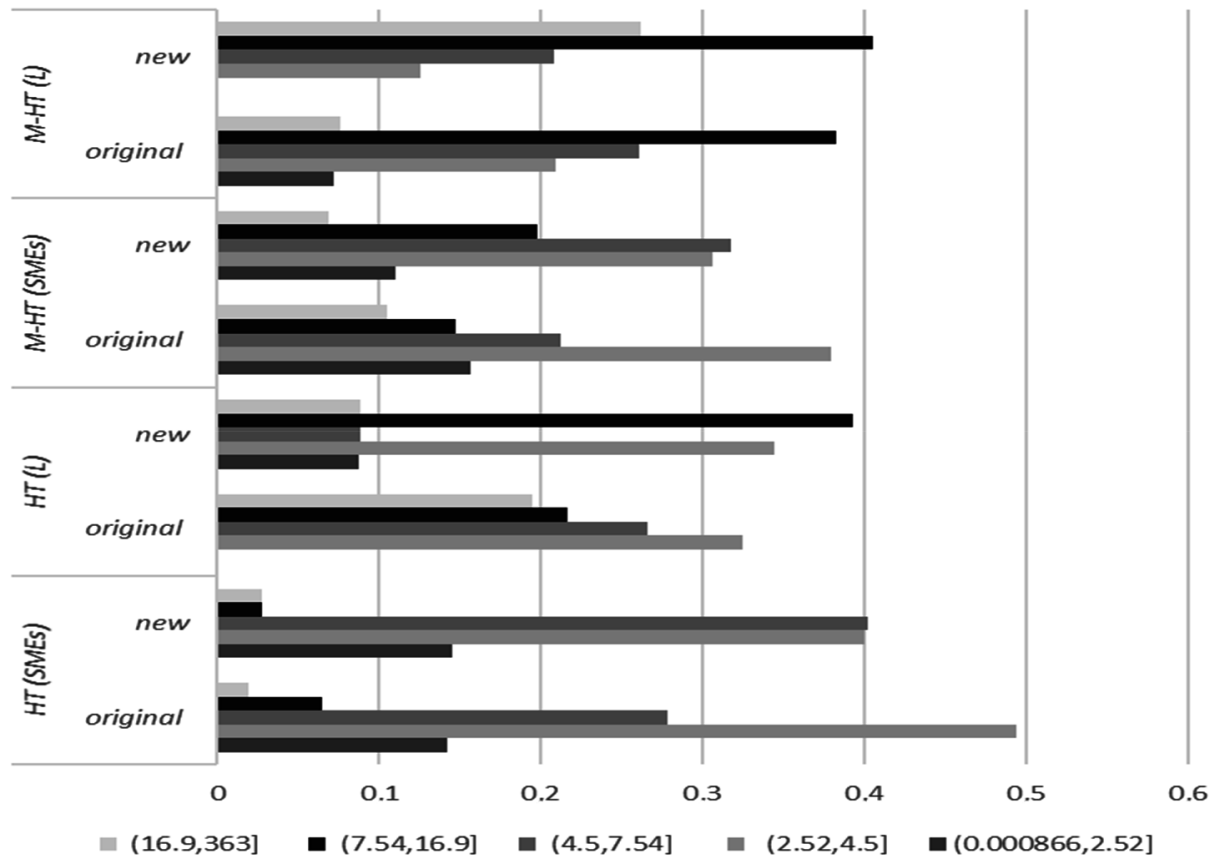

Figure 2. Probability and its change of the output for HT and M-HT enterprises of different size categories (SMEs and L -large) (source: authors' calculation)

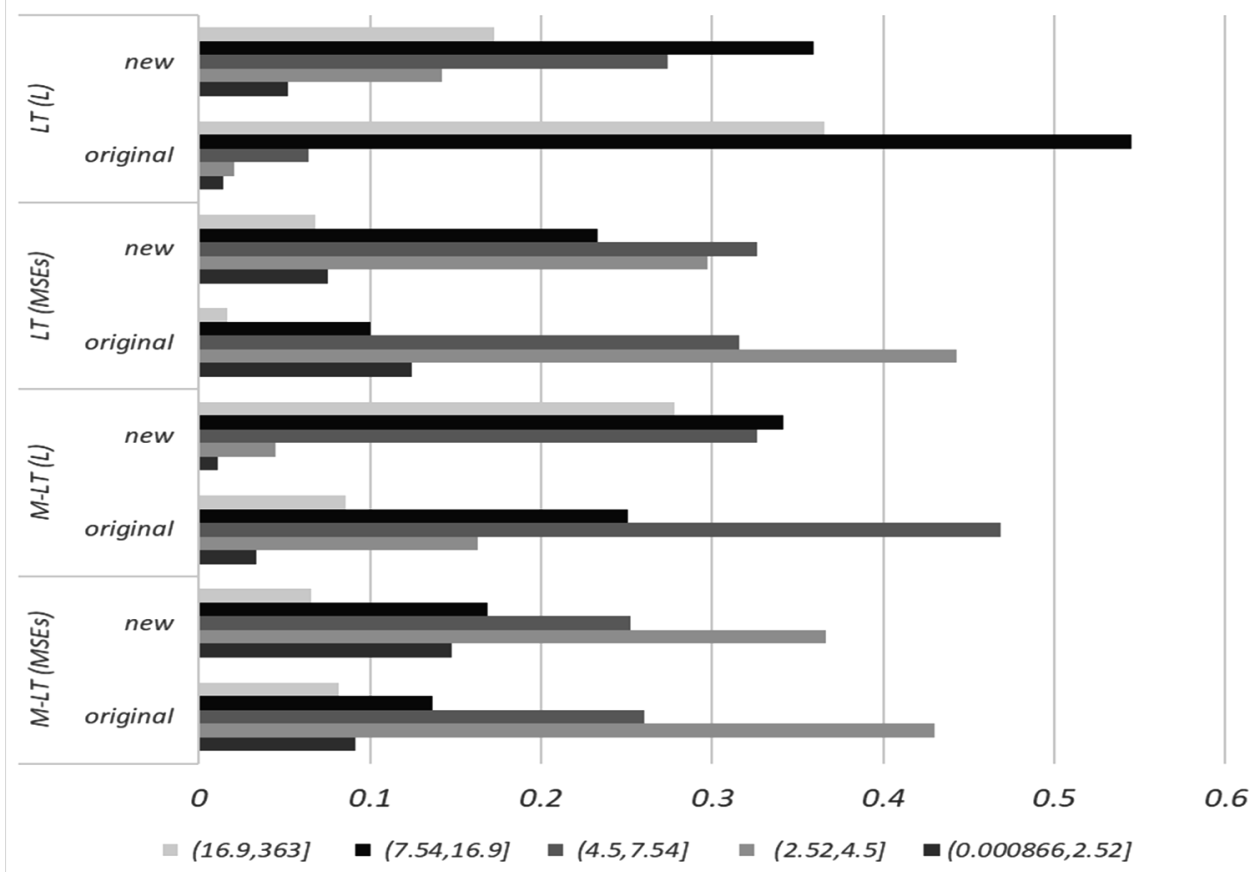

Figure 3. Probability and its change of the output for M-LT and LT enterprises of different size categories (SMEs and L -large) (source: authors' calculation) 
The most dramatic impact of shift c.l.ratio was found for the labour productivity (output). Figures 2 and 3 were drawn depicting output value intervals, including the probabilities of reaching the values for different types and sizes of enterprises.

As Figure 2 revealed, the shift of c.l.ratio into the following interval (the basis is the interval of the mean value of c.l.ratio of different categories and sizes) causes different changes to SMEs compared to large enterprises.

In HT small and medium-sized enterprises, the probability that the output would range $(2.25,4]$ decreased. On the other hand, the probability that the output would range in a higher interval $(4.5,7.54]$ increased (approximately by 0.12$)$. The same result was reported for M-HT SMEs (an increase of approximately 0.10). An important factor here can be the flexibility of SMEs (Mura et al., 2017).

In large M-HT enterprises, the starting interval of output values is likely to be higher, compared to SMEs $(7.54,16.9]$. As the c.l.ratio shifts, the probability increased at this interval, while the probability of achieving higher labour productivity increased significantly, i.e. in the interval $(16.9,363]$, by about 0.19 . Interestingly, for the HT enterprises, labour productivity values are most likely lower than for M-HTs. This may be due to higher demand for skilled employees (Eichhorst et al., 2017) and hence higher personnel costs.

However, if a technology-intensive investment would be implemented, a major change in the labour productivity would occur in large HT enterprises (even a jump increase could be noted), as the output values would fluctuate with the probability of almost 0.4 in the interval $(7.54,16.9]$. High-technology enterprises had a high positive impact on labour productivity growth, but at the same time, they had an impact on the rise of labour intensity. The main reason is higher demand for a skilled workforce that leads to higher wages (Wolter et al., 2015). Figure 3 illustrates the probability that labour productivity figures will be at different intervals in the L-HT and LT enterprises. The results are consistent with the findings of the work of Ortega-Argilés et al. (2015). This work deals with the analysis of R\&D investments and showed that companies in high-tech sectors achieve more productivity gains connected with research investment activities in comparison with companies in low-tech sectors. According to a study by Jiang et al. (2020), there is a relationships among the high- and newtechnology enterprise (their productivity) and the market competition. In industries and regions with more intense market competition, the enterprise with the high- and new-technology have a more stronger motivation effect for increasing productivity, especially labour productivity, than enterprises with a low degree of market competition. In the analysis of Italian companies, Büchi et al. (2020) find that companies in high-tech sectors (mechanical, chemical, electronics or transport industries) showed a higher degree of openness to integrating new technologies based on the Industry 4.0 concept.

In LT small and medium-sized enterprises, investment implementation is related to a significant increase of probabilities within the output of greater values. In such enterprises, a change in capital labour ratio should be related to a change of the output. In M-LT SMEs, an increase of c.l.ratio would not significantly influence the probabilities of values of different intervals.

In large M-LT enterprises, a shift of c.l. ratio interval means a decrease of probabilities of reaching the output in the interval $(4.54,7.54]$ in favour of greater values $(7.54,16.9]$ - 
the probability is increased by 0.1 and for $(16.9,363$ ] by about 0.20 . On the other hand, in large LT enterprises, the probability and achievement of lower ranges of labour productivity values increased.

The results are consistent with the results found by Tello (2017), who presented the positive effects of companies' technology and innovation activities on the labour productivity of low-tech manufacturing companies in Peru.

As reported by Figure 3, there are significant differences between SMEs and large enterprises. Comparing the probabilities and intervals (Figure 2 and 3 ) also reports the differences of different technological intensity. Regarding SMEs, there are not such huge differences in this area.

Vokoun (2016), in his study showed that Czech manufacturing is mostly aimed at Mediumhigh technology (M-HT) and Medium-low technology (M-LT) economic activities. There is a high innovation potential in the Czech Republic. The results suggest that investments will substantially increase the probability of growth of labour productivity just in these enterprises.

\section{Conclusions}

In this paper, we showed that it is possible to use the Bayesian network model to determine the probability of the impact of technological investments on companies' production efficiency using data from 2848 Czech manufacturing companies. The model used takes into account the size of the enterprises and their economic activity (high-technology and lowtechnology enterprises).

The results show that technological investments have the greatest positive impact on the growth of labour productivity and on the decline of labour intensity in low technology enterprises (LT) and medium-low technology enterprises (M-LT). In contrast, the influence of investment growth was insignificant on the indicators of material and services intensity.

Investments in high-technology enterprises (HT) had a high and positive impact on labour productivity growth but labour productivity values are most likely to be lower than for medium-high technology enterprises (M-HT). At the same time, investments in hightechnology enterprises (HT) had a negative impact on the rise of labour intensity.

Regarding small and medium-sized enterprises of all types (categories of technology intensity), the increase in the capital labour ratio would change the probability and the shift of the interval in favour of the performance of the enterprises, i.e. the reduction of the share of personnel costs meaning number of employees.

Technologically intensive investments that generate a significant shift in the capital-labour ratio will therefore have a different impact for small and medium-sized enterprises than for large ones. In SMEs, it means a real lowering of the size of the workforce. However, in large enterprises, it means a change in the structure of workers in favour of more skilled employees, which may also lead to an increase in the share of personnel costs in total cost. The reaction of large companies depends on the degree of technology intensity in contrast to small and medium-sized enterprises.

The first contribution of this paper lies in the analysis of the impact of technology investment on the company's production efficiency, taking into account the technological intensity 
and the size of enterprises (empirical study). The second contribution are the identified factors that are affected most by technological investment in enterprises (labour productivity and labour intensity).

The results obtained from this study are of use to policy makers and companies. The findings help policy makers to direct their public financial support in their high-tech investment policy. The results obtained clearly showed in which companies this support would be the most effective. This paper offers a refined understanding of the relationship between technology investment and companies' production efficiency in manufacturing (labour productivity and cost ratios), especially within the context of a company's size, and insights into technological intensity that managers may consider when formulating the strategies of their company. It enables such relationship to be understood and to contribute to the decision-making of managers in a particular situation in the technology investment field. The theoretical contribution is based on a different approach to evaluating the impact of technological investments on firm's production efficiency.

The limitations of the research are given by the assumptions used in the BNs model. The authors have integrated into this model causal relations of the selected economic indicators affecting the output. Even so, the influence of other factors cannot be excluded. Our approach focuses on the link between technology investment and an enterprise's production efficiency factor in one time period, which remains a severe limitation. Another limitation is the fact that only quantitative variables were considered for the measurement of impact of technology investment on firm's production efficiency. Hence, future research could also use qualitative variables such as an increase of product quality or an increase in market competitiveness to confirm if there are significant differences in the results obtained. However, that would also require a questionnaire survey.

Future investigations may be considered from other states of the European Union to analyse whether the results obtained are similar and perform comparative studies.

\section{Acknowledgements}

This paper was supported by the Grant Agency of Faculty of Economics, the University of South Bohemia IGS13C1.

\section{Conflict of interests}

The authors have not declared any conflict of interests.

\section{References}

Aldieri, L., Cincera, M., Garofalo, A., \& Vinci, C. P. (2008). Micro evidence of the effects of R\&D on labour productivity for large international R\&D firms. International Journal of Manpower, 29(3), 198-215. https://doi.org/10.1108/01437720810878888

Badescu, M., \& Garcés-Ayerbe, C. (2009). The impact of information technologies on firm productivity: Empirical evidence from Spain. Technovation, 29(2), 122-129.

https://doi.org/10.1016/j.technovation.2008.07.005 
Bahrin, M. A. K., Othman, M. F., Azli, N. N., \& Talib, M. F. (2016). Industry 4.0: A review on industrial automation and robotic. Jurnal Teknologi, 78(6-13), 137-143. https://doi.org/10.11113/jt.v78.9285

Barro, R. J., \& Sala-i-Martin, X. (2004). Economic growth (2 $2^{\text {nd }}$ ed.). MIT Press.

Bartodziej, C. J. (2017). The concept industry 4.0. An empirical analysis of technologies and applications in production logistics (pp. 27-50). Springer Gabler, Wiesbaden. https://doi.org/10.1007/978-3-658-16502-4

Basile, R., \& De Benedictis, L. (2008). Regional unemployment and productivity in Europe. Papers in Regional Science, 87(2), 173-192. https://doi.org/10.1111/j.1435-5957.2007.00152.x

Baumann, J., \& Kritikos, A. S. (2016). The link between R\&D, innovation and productivity: Are micro firms different? Research Policy, 45(6), 1263-1274. https://doi.org/10.1016/j.respol.2016.03.008

Becchetti, L., Bedoya, D. a. 1., \& Paganetto, L. (2003). ICT investment, productivity and efficiency: Evidence at firm level using a stochastic frontier approach. Journal of Productivity Analysis, 20(2), 143-167. https://doi.org/10.1023/A:1025128121853

Beugelsdijk, S., Klasing, M. J., \& Milionis, P. (2018). Regional economic development in Europe: The role of total factor productivity. Regional Studies, 52(4), 461-476. https://doi.org/10.1080/00343404.2017.1334118

Birkel, H. S., Veile, J. W., Mueller, J. M., Hartmann, E., \& Voigt, K.-I. (2019). Development of a risk framework for industry 4.0 in the context of sustainability for established manufacturers. Sustainability, 11(2), 384. https://doi.org/10.3390/su11020384

Blažková, I., \& Dvouletý, O. (2019). Investigating the differences in entrepreneurial success through the firm-specific factors. Journal of Entrepreneurship in Emerging Economies, 11(2), 154-76. https://doi.org/10.1108/JEEE-11-2017-0093

Borin, A., \& Mancini, M. (2016). Foreign direct investment and firm performance: An empirical analysis of Italian firms. Review of World Economics, 152, 705-732. https://doi.org/10.1007/s10290-016-0255-z

Brettel, M., Friederichsen, N., Keller, M., \& Rosenberg, N. (2014). How virtualization, decentralization and network building change the manufacturing landscape: An industry 4.0 perspective. International Journal of Mechanical, Industrial Science and Engineering, 8(1), 37-44. https://waset. org/publications/9997144/how-virtualization-decentralization-and-network-building-change-themanufacturing-landscape-an-industry-4.0-perspective

Büchi, G., Cugno, M., \& Castagnoli, R. (2020). Smart factory performance and Industry 4.0. Technological Forecasting and Social Change, 150, 119790. https://doi.org/10.1016/j.techfore.2019.119790

Chung, H. (2018). ICT investment-specific technological change and productivity growth in Korea: Comparison of 1996-2005 and 2006-2015. Telecommunications Policy, 42(1), 78-90. https://doi.org/10.1016/j.telpol.2017.08.005

Dosi, G., Grazzi, M., \& Moschella, D. (2015). Technology and costs in international competitiveness: From countries and sectors to firms. Research Policy, 44(10), 1795-1814. https://doi.org/10.1016/j.respol.2015.05.012

Driffield, N., \& Temouri, Y. (2014). Inward investment and the drivers of post recession recovery in Germany. Jahrbucher Fur Nationalokonomie Und Statistik, 234(6), 775-799. https://doi.org/10.1515/9783110511161-006

Egger, P., \& Pfaffermayr, M. (2001). A note on labour productivity and foreign inward direct investment. Applied Economics Letters, 8(4), 229-232. https://doi.org/10.1080/135048501750103917

Eichhorst, W., Hinte, H., Rinne, U., \& Tobsch, V. (2017). How big is the gig? Assessing the preliminary evidence on the effects of digitalization on the labor market. Mrev Management Revue, 28(3), 298-318. https://doi.org/10.5771/0935-9915-2017-3-298 
EUR-Lex. (2003). Commission recommendation. Official Journal of the European Union L, 124, 36-41. http://eur-lex.europa.eu/eli/reco/2003/361/oj

Eurostat (n.d.). Aggregations of manufacturing based on NACE Rev. 2. Eurostat indicators on High-tech industry and Knowledge - intensive services. Annex 3 - High-tech aggregation by NACE Rev.2. http://ec.europa.eu/eurostat/cache/metadata/Annexes/htec_esms_an3.pdf

Eurostat. (2019). National accounts aggregates by industry. https://appsso.eurostat.ec.europa.eu/nui/ show.do?dataset=nama_10_a64\&lang=en

Filippetti, A., \& Peyrache, A. (2015). Labour productivity and technology gap in European regions: A conditional frontier approach. Regional Studies, 49(4), 532-554. https://doi.org/10.1111/jcms.12864

Freeman, C., \& Perez, C. (1988). Structural crisis of adjustment, business cycles and investment behaviour. G. Dosi, C. Freeman, R. Nelson, G. Silverberg, \& L. Soete (Eds.), Technical change and economic theory (pp. 38-66). Pinter.

Geissbauer, R., Vedso, J., \& Schrauf, S. (2016). Industry 4.0: Building the digital enterprise: 2016 global industry 4.0 survey. $\mathrm{PwC}$, Munich. https://www.pwc.com/gx/en/industries/industries-4.0/landingpage/industry-4.0-building-your-digital-enterprise-april-2016.pdf

Gibson, D. V., \& Naquin, H. (2011). Investing in innovation to enable global competitiveness: The case of Portugal. Technological Forecasting and Social Change, 78(8), 1299-1309. https://doi.org/10.1016/j.techfore.2011.04.004

Girma, S., Greenaway, D., \& Wakelin, K. (2001). Who benefits from foreign direct investment in the UK? Scottish Journal of Political Economy, 48(2), 119-133. https://doi.org/10.1111/1467-9485.00189

Grubicka, J., \& Matuska, E. (2015). Sustainable entrepreneurship in conditions of un (safety) and technological convergence. Entrepreneurship and Sustainability Issues, 2(4), 188-197. https://doi.org/10.9770/jesi.2015.2.4(2)

Guest, R. (2011). Population ageing, capital intensity and labour productivity. Pacific Economic Review, 16(3), 371-388. https://doi.org/10.1111/j.1468-0106.2011.00553.x

Haller, S. A. (2014). Do domestic firms benefit from foreign presence and import competition in Irish services sectors? The World Economy, 37(2), 219-243. https://doi.org/10.1111/twec.12120

Hartemink, A. J. (2001). Principled computational methods for the validation and discovery of genetic regulatory networks [PhD thesis, School of Electrical Engineering and Computer Science]. Massachusetts Institute of Technology.

Hawash, R., \& Lang, G. (2020). Does the digital gap matter? Estimating the impact of ICT on productivity in developing countries. Eurasian Economic Review, 10(2), 189-209. https://doi.org/10.1007/s40822-019-00133-1

Heidenreich, M. (2009). Innovation patterns and location of European low- and medium-technology industries. Research Policy, 38(3), 483-494. https://doi.org/10.1016/j.respol.2008.10.005

Jardim-Goncalves, R., Romero, D., \& Grilo, A. (2017). Factories of the future: challenges and leading innovations in intelligent manufacturing. International Journal of Computer Integrated Manufacturing, 30(1), 4-14.

Jiang, J., Su, P., \& Ge, Z. (2020). The high- and new-technology enterprise identification, marketization process and the total factor productivity of enterprise. Kybernetes. https://doi.org/10.1108/K-11-2019-0743

Kijek, T., \& Kijek, A. (2019). Is innovation the key to solving the productivity paradox? Journal of Innovation \& Knowledge, 4(4), 219-225. https://doi.org/10.1016/j.jik.2017.12.010

Koller, D., \& Friedman, N. (2009). Probabilistic graphical models: principles and techniques. MIT Press.

Kraft, J., \& Kraftova, I. (2012). Innovation - globalization - growth (selected relations). Inzinerine Ekonomika-Engineering Economics, 23(4), 395-405. https://doi.org/10.5755/j01.ee.23.4.2568 
Kraftova, I., Mateja, Z., \& Prasilova, P. (2011). Economic performance: variability of businesses within each industry and among industries. Inzinerine Ekonomika-Engineering Economics, 22(5), 459-467. https://doi.org/10.5755/j01.ee.22.5.964

Leitmanova, I. F., \& Krutina, V. (2009). Monitoring the efficiency of regions - value added utilization (with a View to South Bohemia Region). Ekonomicky Casopis, 57(10), 1018-1037.

Leung, D., Meh, C., \& Terajima, Y. (2008). Firm size and productivity (Working Paper No. 2008, 45). Bank of Canada.

MacDougall, W. (2014). Industrie 4.0: smart manufacturing for the future. Trade \& Invest, Germany. https://www.manufacturing-policy.eng.cam.ac.uk/policies-documents-folder/germany-industrie4-0-smart-manufacturing-for-the-future-gtai/view

Machek, O., \& Hnilica, J. (2012). Total factor productivity approach in competitive and regulated world. Procedia - Social and Behavioral Sciences, 57, 223-230. https://doi.org/10.1016/j.sbspro.2012.09.1178

Mařík, V., Beran, H., Bízková, R., Bunček, M., Burčík, J., Burget, P., \& Burian, J. (2016). Industry 4.0 the initiative for the Czech Republic. The Report Approved by the Government of the Czech Republic on August, 23, 2016.

Müller, J. M., Buliga, O., \& Voigt, K.-I. (2018). Fortune favors the prepared: How SMEs approach business model innovations in Industry 4.0. Technological Forecasting and Social Change, 132, 2-17. https://doi.org/10.1016/j.techfore.2017.12.019

Mura, L., Ključnikov, A., Tvaronavičienė, M., \& Androniceanu, A. (2017). Development trends in human resource management in small and medium enterprises in the Visegrad Group. Acta Polytechnica Hungarica, 14(7), 105-122. https://doi.org/10.12700/APH.14.7.2017.7.7

Nagarajan, R., Scutari, M., \& Lebre, S. (2013). Bayesian networks in $r$ with applications in systems biology. Springer-Verlag, New York. https://doi.org/10.1007/978-1-4614-6446-4

OECD stat. (2019). Gross domestic product (GDP). https://stats.oecd.org/viewhtml.aspx?datasetcode=SNA_TABLE1\&lang=en

OECD/Eurostat. (2005). Oslo manual: guidelines for collecting and interpreting innovation data ( $\left.3^{\text {rd }} \mathrm{ed}.\right)$ OECD Publishing, Paris. http://www.oecd.org/innovation/inno/oslo-manual-guidelines-for-collecting-and-interpreting-innovation-data.htm

Ortega-Argilés, R., Piva, M., \& Vivarelli, M. (2015). The productivity impact of R\&D investment: Are high-tech sectors still ahead? Economics of Innovation and New Technology, 24(3), 204-222. https://doi.org/10.1080/10438599.2014.918440

Parisi, M. L., Schiantarelli, F., \& Sembenelli, A. (2006). Productivity, innovation and R\&D: Micro evidence for Italy. European Economic Review, 50(8), 2037-2061. https://doi.org/10.1016/j.euroecorev.2005.08.002

Pearl, J. (1988). Probabilistic reasoning in intelligent systems: networks of plausible inference. Morgan Kaufmann, Los Angeles. https://doi.org/10.1016/B978-0-08-051489-5.50008-4

Poor, P., \& Basl, J. (2019, February 5-6). Readiness of companies in relation to industry 4.0 implementation. In P. Jedlicka, P. Maresova, \& I. Soukal (Eds.), International Scientific Conference "Hradec Economic Days" (Vol. 9, pp. 236-248). Univ Hradec Kralove. https://doi.org/10.36689/uhk/hed/2019-02-024

Preenen, P., Vergeer, R., Kraan, K., \& Dhondt, S. (2015). Labour productivity and innovation performance: The importance of internal labour flexibility practices. Economic and Industrial Democracy, 38, 1-23. https://doi.org/10.1177/0143831X15572836

Ramírez, S., Gallego, J., \& Tamayo, M. (2019). Human capital, innovation and productivity in Colombian enterprises: A structural approach using instrumental variables. Economics of Innovation and New Technology, 29(6), 1-18. https://doi.org/10.1080/10438599.2019.1664700 
Río, F. D., \& Lores, F. X. (2019). The decline in capital efficiency and labour share. Economica, 86(344), 635-662. https://doi.org/10.1111/ecca.12279

Romer, P. (1990). Endogenous technological change. Journal of Political Economy, 98(5), 71-102. https://doi.org/10.1086/261725

Rüßmann, M., Lorenz, M., Gerbert, P., Waldner, M., Justus, J., Engel, P., \& Harnisch, M. (2015). Industry 4.0: The future of productivity and growth in manufacturing industries. Consulting Group, Boston.

Scutari, M. (2010). Learning bayesian networks with the bnlearn r package. Journal of Statistical Software, 35(3), 1-22. https://doi.org/10.18637/jss.v035.i03

Scutari, M. (2017). Bayesian network constraint-based structure learning algorithms: Parallel and optimized implementations in the bnlearn R package. Journal of Statistical Software, 77(2), 1-20. https://doi.org/10.18637/jss.v077.i02

Scutari, M., \& Denis, J. B. (2014). Bayesian networks with examples in $r\left(1^{\text {st }}\right.$ ed.). CRC Press, Taylor \& Francis Group, Boca Raton. https://doi.org/10.1201/b17065

Seo, H. S., \& Kim, Y. (2020). Intangible assets investment and firms' performance: Evidence from small and medium-sized enterprises in Korea. Journal of Business Economics and Management 20(2), 421-445. https://doi.org/10.3846/jbem.2020.12022

Spiezia, V. (2012). ICT investments and productivity: Measuring the contribution of ICTS to growth. OECD Journal: Economic Studies, 2012(1), 199-211. https://doi.org/10.1787/eco_studies-2012-5k8xdhj4tv0t

Stock, T., \& Seliger, G. (2016). Opportunities of sustainable manufacturing in industry 4.0. In G. Seliger, H. Kohl, \& J. Mallon (Eds.), $13^{\text {th }}$ Global Conference on Sustainable Manufacturing - Decoupling Growth from Resource Use. Procedia CIRP, 40, 536-541. https://doi.org/10.1016/j.procir.2016.01.129

Stundziene, A., \& Saboniene, A. (2019). Tangible investment and labour productivity: Evidence from European manufacturing. Economic Research-Ekonomska Istraživanja, 32(1), 3519-3537. https://doi.org/10.1080/1331677X.2019.1666024

Syverson, C. (2011). What determines productivity? Journal of Economic Literature, 49(2), 326-365. https://doi.org/10.1257/jel.49.2.326

Takahashi, T. (2012). Capital growth paths of the neoclassical growth model. PLOS ONE, 7(11), e49484. https://doi.org/10.1371/journal.pone.0049484

Tambe, P., \& Hitt, L. (2011). The productivity of information technology investments: New evidence from IT labor data. Information Systems Research, 23(3), 599-848. https://doi.org/10.1287/isre.1110.0398

Tello, M. (2015). Firms' innovation, public financial support, and total factor productivity: The case of manufactures in Peru. Review of Development Economics, 19.

Tello, M. (2017). Innovation and productivity in services and manufacturing firms: The case of Peru: Mario D. Tello. CEPAL Review, 121, 69-86. https://doi.org/10.18356/a4c7eea5-en

Thatcher, M. E., \& Oliver, J. R. (2001). The impact of technology investments on a firm's production efficiency, product quality, and productivity. Journal of Management Information Systems, 18(2), 17-45. https://doi.org/10.1080/07421222.2001.11045685

Trexima. (2018). The role and level of labour productivity in the Czech Republic. https://ipodpora.odbory. info/soubory/dms/ukony/22311/6/Studie\%20-\%20Role\%20a\%20\%c3\%barovn\%c4\%9b\%20produktivity\%20pr\%c3\%a1ce\%20v\%20\%c4\%8cR.pdf

Ulku, H. (2007). R\&D, innovation, and growth: Evidence from four manufacturing sectors in OECD countries. Oxford Economic Papers, 59(3), 513-535. https://doi.org/10.1093/oep/gpl022

Van Ark, B. (2016). The productivity paradox of the new digital economy. International Productivity Monitor, 31, 3-18. 
Van Beveren, I. (2012). Total factor productivity estimation: A practical review. Journal of Economic Surveys, 26(1), 98-128. https://doi.org/10.1111/j.1467-6419.2010.00631.x

Vokoun, M. (2016) Innovation behaviour of firms in a small open economy: The case of the Czech manufacturing industry. Empirica, 43(1), 111-139. https://doi.org/10.1007/s10663-015-9296-0

Wakelin, K. (2001) Productivity growth and R\&D expenditure in UK manufacturing firms. Research Policy, 30(7), 1079-1090. https://doi.org/10.1016/s0048-7333(00)00136-0

Wolter, M. I., Mönnig, A., Hummel, M., Schneemann, C., Weber, E., Zika, G., \& Neuber-Pohl, C. (2015). Industry 4.0 and the consequences for labour market and economy: Scenario calculations in line with the BIBB-IAB qualifications and occupational field projections. Institute for Employment Research, Nuremberg, Germany.

Zawislak, P. A., Fracasso, E. M., \& Tello-Gamarra, J. (2018). Technological intensity and innovation capability in industrial firms. Innovation \& Management Review, 15(2), 189-207.

https://doi.org/10.1108/INMR-04-2018-012 